\title{
Respiratory Symptoms and Pulmonary Function Testes in Lead Exposed Workers
}

\author{
Mohammad Reza Khazdair ${ }^{1}$, Mohammad Hossein Boskabady ${ }^{1^{*}}$, Reza Afshari ${ }^{2}$, Bita Dad- \\ pour ${ }^{2}$, Amir Behforouz ${ }^{1}$, Mohammad Javidi ${ }^{1}$, Abbasali Abbasnezhad ${ }^{1}$, Valiallah Moradi ${ }^{3}$, \\ Seyed Saleh Tabatabaie ${ }^{4}$ \\ ${ }^{1}$ Department of Physiology, School of Medicine and pharmaceutical Research Center, Mashhad University of Medical Sciences., Mashhad, IR Iran \\ ${ }^{2}$ Department of Toxicology, School of Medicine, Mashhad University of Medical Sciences, Mashhad, IR Iran \\ ${ }^{3}$ Toxicology Laboratory, Imam Reza Hospital, Mashhad, IR Iran \\ ${ }^{4}$ Iranian Red Crescent Hospital, Dubai, UAE \\ * Corresponding author: Mohammad Hossein Boskabady, Department of Physiology, School of Medicine and pharmaceutical Research Center, Mashhad \\ University of Medical Sciences, Postal Code: 9177948564, Mashhad, IR Iran. Tel.: +98-5118002221, Fax: +98-5118828564, E-mail: m-boskabady@mums.ac.ir
}

\section{A B S T R A C T}

Background: The exposure to noxious agwents such as lead my cause lung disorders.

objectives: In the present study, pulmonary function tests and self-reported respiratory symptoms in lead exposure workers were compared with matched control subjects.

Materials and Methods: The frequency of respiratory symptoms were evaluated in a sample of 108 lead exposure workers and 100 control subjects with similar age using a questionnaire including questions on respiratory symptoms in the past year. Pulmonary function tests (PFT) were also measured in lead exposure workers and in controls.

Results: Most lead exposure workers (63\%) reported work-related respiratory symptoms. Chest tightness (26\%), cough (17\%)and sputum (16\%) were the most common symptoms and only 6\% of lead exposure workers reported wheezing $(\mathrm{P}<0.001$ for all case except wheezing). Most PFT values were also significantly reduced among lead exposure workers ( $\mathrm{P}<0.05$ to $\mathrm{P}<0.001$ except MEF75, MEF50, MEF25, and MMEF. The lead concentration in urine and serum of lead exposure workers were significantly higher than control(P<0.001 for both cases).

Conclusions: These results showed that c lead exposure workers have higher frequencies of respiratory symptoms higher serum and urine lead concentration but lower PFT values.

Keywords: Lead; Signs and Symptoms, Respiratory; Respiratory Function Tests

\section{Background}

In spite of effort to limit for use of lead components industry services, this heavy metal remains as one of the industrial environmental pollution (1-3). Although the effect environmental pollution on morphology and respiratory physiology is demonstrated the effects of environmental lead on respiratory system is controversial and more studies needed to clarify this effect $(4,5)$. It is suggested that lead pollution may contribute in patho- genesis of pulmonary cancers, asthma, COPD however, there is not confident result in this regard yet (6-8). Epidemiological studies suggests that lead may play a role in causing asthma as the incidence of asthma in workers exposed to lead as well as children that live in high levels of lead pollution places is increased $(9,10)$. In addition these studies showed significant relationship between blood lead concentration and $\operatorname{IgE}(9,10)$.

Increase of IgE and some inflammatory cytokines in se-

Article type: Research Article; Received: 11 Jan 2012, Revised:17 Mar 2012, Accepted: 25 Mar 2012; DOI: 10.5812/ircmj.4134

-Implication for health policy/practice/research/medical education:

In this study pulmonary function tests and self-reported respiratory symptoms in lead exposure workers were compared with matched control subjects.

-Please cite this paper as:

Khazdair MR, Boskabady MH, Afshari R, Dadpour B, Behforouz A, Javidi M, et al. Respiratory Symptoms and Pulmonary Function Testes in Lead Exposed Workers. Iran Red Cres Med J.2012;14(11):727-32. DOI: 10.5812/ircmj.4134 
rum of laboratory models and children exposed to lead as well as release of inflammatory mediator from the cells and macrophages exposed to lead in a cell culture model were reported. However, some reports indicated no change or even decrease of serum immunoglobins in laboratory models exposer lead (11-16). Therefore more studies are need for evaluation of immunotoxic effect of lead exposure and the role of this metal in incidence and severity of asthma and other respiratory diseases. In addition in experimental studies on animal models exposed to lead respiratory system morphologic changes as well as increased tracheal responsiveness was observed which could be demonstrate the role of lead in pathogenesis pathology of asthma disease but definite document regarding the role of lead in pathology of asthma or other respiratory diseases is not available yet (17).

\section{Objectives}

Therefore, in the present study pulmonary function tests and self-reported respiratory symptoms in lead exposed workers of a car battery manufactory were compared with matched control subjects.

\section{Materials and Methods}

\subsection{Subjects}

One hundred eight lead exposed workers of a car battery manufactory (mean age $\pm S D ; 31.31 \pm 6.91,102$ male and 6 female) and 100 control subjects (mean age \pm SD; $34.13 \pm 7.81,92$ male and 8 female) were studied. The control subjects were chosen from visitors to the Medical Center with approximately the same age as lead exposed workers. All lead exposed workers employed in a car battery manufactory for 1 to 13 years (mean employment duration $\pm S D ; 4.65 \pm 2.99$ years). All workers were worked 8 hours in a day, 6 day in each week. All studied subjects were non-smokers; none reported a recent respiratory infection or gave a history of asthma or COPD prior to lead exposure. The study was approved by the Ethical Committee of the institution of Mashhad University of Medical Sceinces, and each subject gave informed consent.

\subsection{Protocol}

A Farsi questionnaire was used to assess the prevalence and severity of respiratory (wheezing, tightness, cough and sputum), ( Table 1 ). Questionnaire on respiratory symptoms was designed in accordance with several previous questionnaires of similar studies by expert groups (18-23). Common risk factors like smoking habit, atopy and history of allergic reactions were also asked. Moreover, the participants answered questions regarding all employment period (working hours per day and total working period).

\begin{tabular}{|c|c|}
\hline Symptom and Frequency & Score \\
\hline \multicolumn{2}{|l|}{ Wheezing } \\
\hline None & 0 \\
\hline $\begin{array}{l}\text { During mild exercise } \\
\text { (walking) }\end{array}$ & 1 \\
\hline During heavy exercise & 2 \\
\hline At rest & 3 \\
\hline \multicolumn{2}{|l|}{ Cough } \\
\hline None & 0 \\
\hline $\begin{array}{l}\text { During mild exercise } \\
\text { (walking) }\end{array}$ & 1 \\
\hline During heavy exercise & 2 \\
\hline At rest & 3 \\
\hline \multicolumn{2}{|l|}{ Tightness } \\
\hline None & 0 \\
\hline $\begin{array}{l}\text { During mild exercise } \\
\text { (walking) }\end{array}$ & 1 \\
\hline During heavy exercise & 2 \\
\hline At rest & 3 \\
\hline \multicolumn{2}{|l|}{ Sputum } \\
\hline None & 0 \\
\hline $\begin{array}{l}\text { Small volumes of non-pu- } \\
\text { rulent sputum }\end{array}$ & 1 \\
\hline $\begin{array}{l}\text { Large volumes of non-pu- } \\
\text { rulent sputum }\end{array}$ & 2 \\
\hline Purulent sputum & 3 \\
\hline Total score & 12 \\
\hline
\end{tabular}

Pulmonary function tests in lead exposed workers and control subjects were measured using a spirometer with a pneumotachograph sensor (Model ST90, Fukuda, Sangyo Co., Ltd. Japan). Prior to pulmonary function testing, the PFT measurement technique was demonstrated by the operator, and subjects were encouraged and supervised throughout test performance. Pulmonary function testing was performed using the acceptability standards outlined by the American Thoracic Society (ATS) with subjects in a standing position and wearing nose clips (24). Measurements of PFT values were carried out between 1000 and 1700 hours. Pulmonary function tests were performed three times in each subject. The highest level for forced vital capacity (FVC), forced expiratory volume in one second (FEV1), peak expiratory flow (PEF), maximal mid expiratory flow (MMEF) and maximal expiratory flow at 75\%, 50\%, and 25\% of the FVC (MEF75, MEF50, and MEF25 respectively) were taken independently from 
the three measurements.

\subsection{Measurement of Serum and Urine Lead Con- centration}

\subsubsection{Serum Sampling}

By venepuncture $3-4 \mathrm{ml}$ of whole blood were drawn into a plastic syringe. A1ml sample was placed in a plastic tube containing K3EDTA and stored at $4^{\circ} \mathrm{C}$ for subsequent determination of whole blood lead. The remainder of the sample, placed in another Tube also containing K3EDTA, was immediately centrifuged at $800 \mathrm{rev} / \mathrm{min}$ for $15 \mathrm{~min}$; the plasma obtained was stored at $-20^{\circ} \mathrm{C}$ for subsequent lead determination.

\subsubsection{Urine Sampling}

About $50 \mathrm{ml}$ of urine sample was transferred into a metal-free plastic bottle immediately after collection in a clinical paper cup, and then acidified by the addition of $200 \mu 1$ nitric acid. The urine samples were kept frozen until analysis.

\subsubsection{Atomic Absorption Spectrometry (AAS)}

Sample is dissolved in an acid mixture. The resulting solutions were analyzed by Atomic Absorption Spectrometry. Standards solutions with known concentrations of the elements were used to establish calibration data. Calibration was verified through analysis of NIST or NIST traceable certified reference materials. All determinations were performed using a Perkin Elmer atomic absorption spectrophotometer Model 3030 (made in US) with a lead hollow cathode lamp (HCL) and (EDL) was used, equipped with a HGA 400 graphite furnace and a deuterium background corrector. Nitrogen was used as purge gas for the graphite furnace.

\subsection{Data Analysis}

The data of age, PFT values, and lead concentration were expressed as mean \pm SD and data of respiratory and allergic symptoms as percentage of each group having the corresponding symptom. Differences in the data of symptoms between lead exposed workers and control group were tested by Chi-Squared analysis (2X2 contingency tables). Differences in the data of symptom between lead exposed workers and control group and also between rest and working periods were tested by calculating Relative Risk and the 95\% Confidence Intervals (RR, 95\% CI.). The data of PFT values and serum concentration between lead exposed workers and control groups were tested using unpaired t tests. The correlation between PFT values and respiratory symptoms with urine and serum lead concentration was performed using least square test. A two-sided $p$ value of 0.05 was the criterion for statistical significance. All analyses were performed with SPSS soft- ware (version 11.5, SPSS Inc. USA).

\section{Results}

4.1. Comparison of Respiratory and Allergic Symptoms Between Lead Exposed Workers and Control Group

Most lead exposure workers (63\%) reported work-related respiratory symptoms. Sputum (16\%), cough (17\%), wheezing (6\%) and Tightness of breathe (26\%). The prevalence of sputum, cough and tightness were higher in lead exposed workers compared to control group $(\mathrm{P}<0.001$ for all case) but there was no significant difference in the prevalence of wheezing between two groups ( Figure 1a). The severities of all respiratory symptoms were also higher in lead exposed workers compared to control group for sputum, cough and tightness $(\mathrm{P}<0.001$ for all case, Figure $1 b$ )
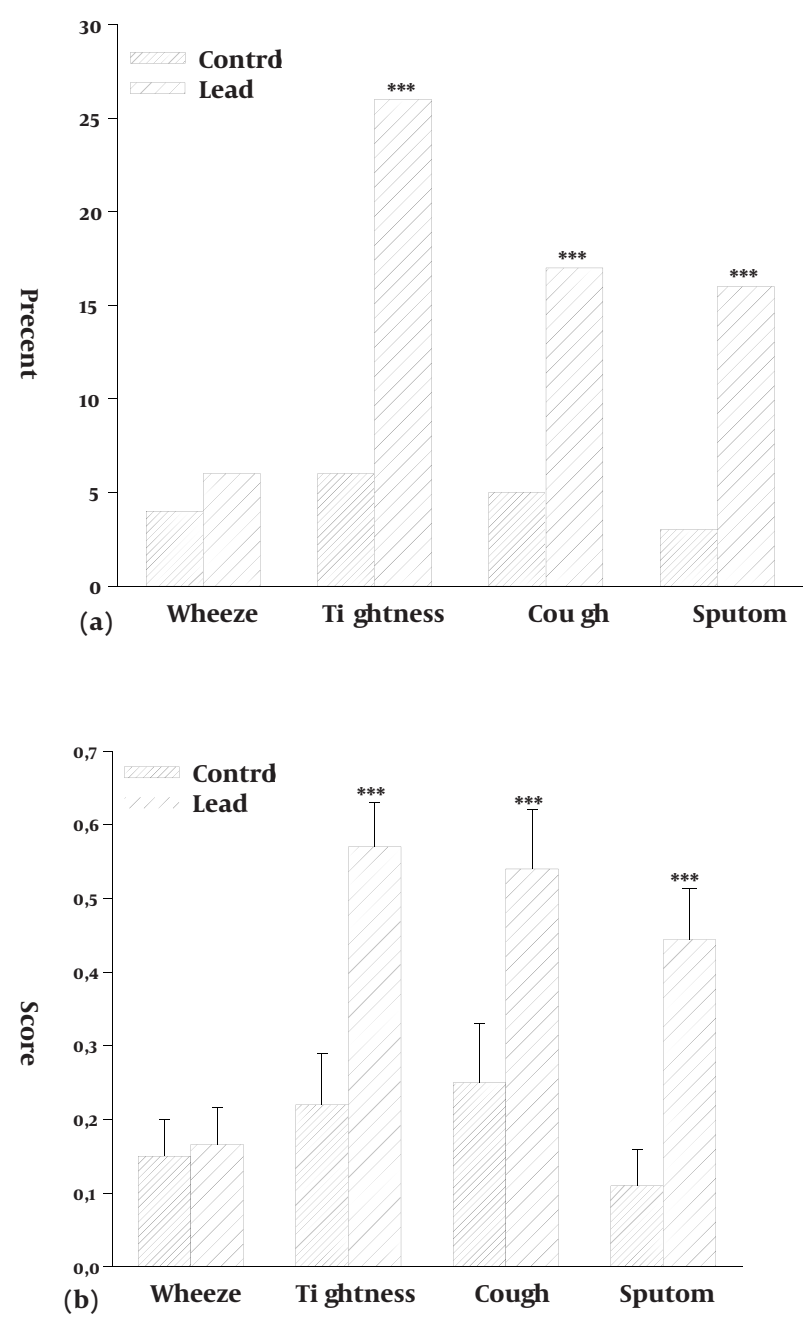

Figure 1. Comparison of prevalence (a) and severity (b) of respiratory symptoms between control subjects and lead exposed workers (for Control group, $\mathrm{n}=100$ and lead exposed group, $\mathrm{n}=108)$. ${ }^{* * *}: \mathrm{P}<0.001$ 


\subsection{Comparison of PFT Values Between Lead Ex- posed Workers and Control Group}

The values of FVC (forced vital capacity), FEV1 (forced expiratory volume) and PEF (peak expiratory flow) were lower in lead exposed workers than control subjects $(\mathrm{P}<$ 0.05 to $\mathrm{P}<0.001$, Figure 2 ). However, there was no significant difference between MMEF, MEF75, MEF50, and MEF25 between two groups ( Figure 2 ).

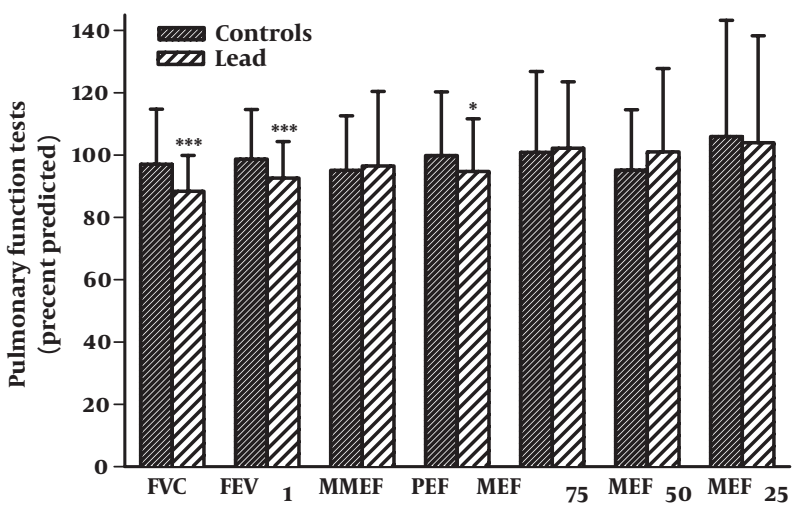

Figure 2. Comparison of pulmonary functional tests (PFT) between control subjects and lead exposedworkers (for Control group, $\mathrm{n}=100$ and lead exposed group, $\mathrm{n}=108)$. Values were presents as mean \pm SD. FVC: forced vital capacity, FEV1: forced expiratory volume in one second, MMEF maximal mid expiratory flow, PEF: peak expiratory flow, MEF75, MEF50, and MEF25: maximal expiratory flow at $75 \%, 50 \%$, and $25 \%$ of the FVC, respectively. Statistical significance between two groups; *: P < 0.05, ${ }^{* * *}$ : P $<0.001$

\subsection{Comparison of Serum and Urine Lead Concen- tration Between Lead Exposed Workers and Con- trol Group}

The concentration of urine and serum lead in lead exposed workers were higher than those of control subjects $(\mathrm{P}<0.0001$, Table 2$)$.

Table 2. Comparison of urine lead and serum lead between control subjects and lead exposed workers

\begin{tabular}{|c|c|c|c|}
\hline Parameter & Control & $\begin{array}{l}\text { Lead ex- } \\
\text { posed Work- } \\
\text { ers }\end{array}$ & Stat. dif. \\
\hline Urine lead & $23.560 \pm 1.63$ & $76.84 \pm 5.76$ & $\mathrm{P}<0.0001$ \\
\hline Serum lead & $72.51 \pm 3.46$ & $370.50 \pm 22.182$ & $\mathrm{P}<0.0001$ \\
\hline
\end{tabular}

\subsection{Correlation Between PFT Values and Respira- tory Symptoms With Urine and Serum Lead Con- centration in Lead Exposed Workers}

The serum lead concentration were correlated with all PFT values except FEV1 $(\mathrm{P}<0.05$ to $\mathrm{P}<0.01)$, but PFT values were correlated with urine lead concentration for only MMEF and MEF25 ( $\mathrm{P}<0.05$ for all cases, Table 3 ).

Table 3. Correlation between PFT values with urine (Urin L) and serum (Serum L) lead concentration in lead exposed workers

\begin{tabular}{|c|c|c|c|c|c|c|c|c|c|c|c|c|c|c|}
\hline \multirow[t]{2}{*}{ PFT Values } & \multicolumn{2}{|l|}{ FVC } & \multicolumn{2}{|l|}{ FEV1 } & \multicolumn{2}{|c|}{ MMEF } & \multicolumn{2}{|l|}{ PEF } & \multicolumn{2}{|c|}{ MEF75 } & \multicolumn{2}{|c|}{ MEF50 } & \multicolumn{2}{|c|}{ MEF25 } \\
\hline & $\mathrm{r}$ & $\mathrm{p}$ & $\mathrm{R}$ & $\mathrm{P}$ & $\mathrm{r}$ & $\mathrm{p}$ & $\mathrm{r}$ & $\mathrm{P}$ & $\mathrm{r}$ & $\mathrm{p}$ & $\mathrm{r}$ & $\mathrm{p}$ & $\mathrm{r}$ & $\mathrm{p}$ \\
\hline Urine L & 0.12 & 0.31 & 0.02 & 0.88 & 0.22 & 0.05 & 0.14 & 0.20 & 0.12 & 0.29 & 0.19 & 0.09 & 0.24 & 0.03 \\
\hline Serum L & 0.21 & 0.05 & 0.02 & 0.85 & 0.28 & 0.01 & 0.21 & 0.05 & 0.22 & 0.05 & 0.30 & 0.01 & 0.25 & 0.02 \\
\hline
\end{tabular}

\section{Discussion}

The results of the present study showed significant greater respiratory symptoms compared to control subjects. The severities of respiratory symptoms also were significantly higher among lead exposed workers than controls. In addition PFT values in lead exposed worker were lower compared to control group. The urine and serum lead concentration in lead exposed workers was significantly higher than control subjects. There was also significant correlation between serum lead concentration and PFT values. These results indicate the effect of the exposures to lead on respiratory status of these workers and confirms that exposure to lead in work environment induces respiratory disorder.

The increased urine and serum lead concentration in lead exposed workers was supported by the a previous observation indicating severe smoke inhalation of closed-space fires of a tertiary burn center was associated with a more than 2-fold increase in blood lead levels of lead (25). The results of the present study showed high prevalence and severity of Tightness, sputum and cough among lead exposed workers but lower prevalence of wheeze which are more compatible with COPD rather than asthma. These findings are also supported by the results of a previous study showing higher prevalence of respiratory symptoms for phlegm, shortness of breath and diagnosed asthma in industrial workers exposed with lead (6). However, there was no increased likelihood of asthma diagnosis or symptoms among young children with lead poisoning (26). The possible reason for this discrepancy is perhaps the long period of lead exposure in studied workers in the present study. In addition, an elevated incidence of lung cancer was observed in smelter workers exposed to lead (7).

However, the findings of our study more clearly indicate the effect of exposure to lead on respiratory symptoms as 
well as PFT values. There was also significant correlation between serum lead concentration and change of most PFT values. These observations confirm that exposure to lead in environment may responsible for development of respiratory symptoms. In addition reduction of PFT values and existence of respiratory symptoms in lead exposed workers indicate a permanent respiratory change in these workers.

The results of our study showed a considerable reduction in some values of PFT in lead exposed workers compared to control subject. In fact, it was shown that blood lead concentration was associated with increased bronchial hyperresponsivenes (27). In addition, the concentrations of lead, especially over a long period, may cause irreversible morphological alterations in the, rat lung tissue (15). The reason of less obvious reduction in MMEF and MEF75 MEF50, and MEF25 values in lead exposed workers in the present study may indicate the higher effect of lead exposure on larger airways (28). The reason of the greater effect of lead exposure on larger airways may be due to particle size of this heavy metal in the factory environment. The higher effect of lead exposure on FVC, FEV1 and PEF may also indicate that lead exposure may induce COPD like changes in the lung. This conclusion also supported by lower effect of lead exposure on prevalence and severity of wheeze and its higher effect on chest tightness, cough and sputum. The increased blood lead levels of battery and exhaust workers and reduction of their PFT was shown previously which support the results of the present study (29).

In conclusion, the results of this study showed that lead exposure in work environment can cause a higher frequency of respiratory symptoms. PFT values were also significantly reduced among lead exposed workers compared to control subjects indicating a permanent change of respiratory system may occur due to lead exposure. Therefore, the results suggest a relationship of environmental lead exposure and respiratory status.

\section{Acknowledgements}

This study was financially supported by the Research Council of Mashhad University of Medical Sciences.

\section{Funding/Support}

The study was approved by the Ethical Committee of the institution, and each subject gave informed consent.

\section{Financial Disclosure}

There is no any conflict of interest in the present study.

\section{References}

1. Jacobs DE, Wilson J, Dixon SL, Smith J, Evens A. The relationship of housing and population health: a 30-year retrospective analysis. Environ Health Perspect. 2009;117(4):597-604.

2. Needleman H. Lead poisoning. Annu Rev Med. 2004;55:209-22.
3. Landrigan PJ, Schechter CB, Lipton JM, Fahs MC, Schwartz J. Environmental pollutants and disease in American children: estimates of morbidity, mortality, and costs for lead poisoning, asthma, cancer, and developmental disabilities. Environ Health Perspect. 2002;110(7):721-8.

4. Joseph CL, Havstad S, Ownby DR, Peterson EL, Maliarik M, McCabe MJ, et al. Blood lead level and risk of asthma. Environ Health Perspect. 2005;113(7):900-4.

5. Call RS, Smith TF, Morris E, Chapman MD, Platts-Mills TA. Risk factors for asthma in inner city children. JPediatr. 1992;121(6):862-6.

6. Bener A, Almehdi AM, Alwash R, Al-Neamy FR. A pilot survey of blood lead levels in various types of workers in the United Arab Emirates. Environ Int. 2001;27(4):311-4.

7. Englyst V, Lundstrom NG, Gerhardsson L, Rylander L, Nordberg G. Lung cancer risks among lead smelter workers also exposed to arsenic. Sci Total Environ. 2001;273(1-3):77-82.

8. Gould E. Children's Lead Poisoning and Asthma. Econ Policy Inst Working Paper. 2005.

9. Dietert RR, Lee JE, Hussain I, Piepenbrink M. Developmental immunotoxicology of lead. Toxicol Appl Pharmacol. 2004;198(2):8694.

10. Anetor JI, Adeniyi FA. Decreased immune status in Nigerian workers occupationally exposed to lead. Afr J Med Med Sci. 1998;27(3-4):169-72.

11. Chen S, Miller T, Golemboski K, Dietert R. Suppression of macrophage metabolite production by lead glutamate in vitro is reversed by meso-2, 3-dimercaptosuccinic acid(DMSA). In vitro toxicology.1997;10(3):351-8.

12. Gupta N, Fahim M. Lead acetate induced contraction in rat tracheal smooth muscle is independent of epithelium. Indian Physiol Pharmacol. 2007;51(1):49-54.

13. Heo Y, Parsons PJ, Lawrence DA. Lead differentially modifies cytokine production in vitro and in vivo. Toxicol Appl Pharmacol. 1996;138(1):149-57.

14. Miller TE, Golemboski KA, Ha RS, Bunn T, Sanders FS, Dietert RR Developmental exposure to lead causes persistent immunotoxicity in Fischer 344 rats. Toxicol Sci. 1998;42(2):129-35.

15. Onarlioğlu B, Onarlioğlu T, Erdal S. The effect of lead inhalation on rat lung morphology. Tr J Med Sci.1998;29:617-22.

16. Zelikoff JT, Parsons E, Schlesinger RB. Inhalation of particulate lead oxide disrupts pulmonary macrophage-mediated functions important for host defense and tumor surveillance in the lung. Environ Res. 1993;62(2):207-22.

17. Salovsky P, Shopova V, Dancheva V, Pandurska A, Marev R. Bronchoalveolar lavage fluid in rats treated intratracheally with lead acetate. Bull Environ Contam Toxicol.1994;52(6):912-8.

18. Bellia V, Pistelli F, Giannini D, Scichilone N, Catalano F, Spatafora $\mathrm{M}$, et al. Questionnaires, spirometry and PEF monitoring in epidemiological studies on elderly respiratory patients. Eur Respir $J$ Suppl. 2003;40:21-7.

19. Boskabady MH, Farhadi J. The possible prophylactic effect of $\mathrm{Ni}$ gella sativa seed aqueous extract on respiratory symptoms and pulmonary function tests on chemical war victims: a randomized, double-blind, placebo-controlled trial. J Altern Complement Med.2008;14(9):1137-44.

20. Boskabady MH, Karimiani EG, Vostacolaei HA. Respiratory symptoms and pulmonary function changes among carpet weavers in Iran. Int J Occup Environ Health. 2007;13(4):369-75.

21. Boskabady MH, Kolahdoz GH. Prevalence of asthma symptoms among the adult population in the city of Mashhad (north-east of Iran). Respirology. 2002;7(3):267-72.

22. National Institutes of Health, editor. Global strategy for asthma management and prevention. NHBLI workshop report; 2007; Bethesda, MD.

23. Turcotte H, Langdeau JB, Bowie DM, Boulet LP. Are questionnaires on respiratory symptoms reliable predictors of airway hyperresponsiveness in athletes and sedentary subjects? J Asthma. 2003;40(1):71-80

24. Standardization of Spirometry, 1994 Update. American Thoracic SocietyStandardization of Spirometry, 1994 Update. American Thoracic Society Am J Respir Crit Care Med.1995;152(3):1107-36.

25. Lahn M, Sing W, Nazario S, Fosberg D, Bijur P, Gallagher EJ. In- 
creased blood lead levels in severe smoke inhalation. Am J Emerg Med.2003;21(6):458-60.

26. Myers SN, Rowell B, Binns HJ. Lead poisoning and asthma: an examination of comorbidity. Arch Pediatr Adolesc Med. 2002;156(9):863-6.

27. Min JY, Min KB, Kim R, Cho SI, Paek D. Blood lead levels and increased bronchial responsiveness. Biol Trace Elem Res. 2008;123(1
3):41-6.

28. Cotes JE. Lung Function: Assessment And Application In Medicine. London: John Wiley \& Sons; 1993.

29. Bagci C, Bozkurt AI, Cakmak EA, Can S, Cengiz B. Blood lead levels of the battery and exhaust workers and their pulmonary function tests. Int J Clin Pract. 2004;58(6):568-72. 